\title{
Failover Gateway Menggunakan Protokol Virtual Router Redundancy Protocol (VRRP) pada Mikrotik Router
}

\author{
Herman Kuswanto $^{\# 1}$, Taufik Rahman ${ }^{* 2}$ \\ \#Program Studi Teknik Informatika STMIK Nusa Mandiri Jakarta \\ Jl. Damai No. 8 Warung Jati Barat (Margasatwa), Jakarta Selatan, Indonesia \\ ${ }^{1}$ herman.hko@nusamandiri.ac.id \\ *Program Studi Sistem Informasi Universitas Bina Sarana Informatika \\ Jl Kamal Raya No. 18 Ringroad Barat, Cengkareng, Jakarta Barat, Indonesia \\ ${ }^{2}$ taufik.tkr@bsi.ac.id
}

\begin{abstract}
Abstrak - Kebutuhan penggunaan jaringan komputer saat ini sudah semangkin dominan dalam pekerjaan keseharian, baik dalam suatu institusi ataupun perusahaan, permasalahan pada router akan menyebabkan terhentinya proses komunikasi antar client maupun client dengan server sehingga menyebabkan terganggunya proses kinerja institusi ataupun perusahaan tersebut. Penggunaan infrastruktur yang baik tidak akan menjamin jaringan akan aman dari gangguan, seperti pada penggunaan router, perlu adanya mekanisme link backup untuk menjaga agar koneksi jaringan tetap terjaga, sama halnya seperti koneksi internet yang harus mempunyai link backup, router juga harus mempunyai perangkat backup yang bertujuan untuk mencegah jika tiba-tiba router bermasalah atau rusak, untuk mengatasi permasalahan tersebut perlu dibuatnya sebuah sistem failover pada router. Pada penerapanya digunakan sebuah protokol yang terdapat pada mikrotik router yaitu virtual router redundancy protocol (VRRP), yang digunakan untuk tujuan redudancy antar router. Dari hasil percobaan yang telah dilakukan, dengan penerapan failover pada router menggunakan protokol VRRP, downtime pada jaringan jika terjadi masalah pada router akan cepat teratasi dan komunikasi pada jaringan tidak akan terpengaruh jika ada salah satu router yang bermasalah dikarenakan jika terjadi permasalahan pada salah satu router maka router backup akan berjalan dengan otomatis menggantikan router yang bermasalah.
\end{abstract}

Kata kunci- Jaringan, Router, Mikrotik, Protokol, Vrrp

\section{Pendahuluan}

Penggunaan jaringan komputer merupakan hal yang sangat penting dalam suatu institusi, dengan penggunaan infrastruktur yang memadai tidak menjamin sebuah jaringan akan bagus dan handal, jika tidak diikuti dengan perhatian terhadap infrastuktur yang ada[1]. Router merupakan perangkat yang sangat penting penggunaanya dalam sebuah jaringan[2], fungsi router selain sebagai penghubung antar segment jaringan yang berbeda juga sekaligus sebagai pintu gerbang atau gateway dari jaringan lokal ke jaringan internet[3]. Seperti halnya pada koneksi internet yang harus mempunyai link backup untuk menjaga agar client tetap bisa terkoneksi ke internet dan link internet tetap terjaga[4], penggunaan router pada jaringan yang besar juga perlu adanya link backup untuk menjaga ketersedianan koneksi[5], jika terjadi permasalahan pada router sedangkan link backup router tidak tersedia maka akan berpengaruh pada semua perangkat yang terkoneksi ke jaringan[6], dan jika terjadi permasalahan pada router proses komunikasi antar client atau komunikasi server dengan client tidak dapat dilakukan[7].

Untuk mencegah terjadinya permasalahan pada router yaitu dengan menerapkan metode failover, dengan metode failover, jika terjadi permasalahan pada router primary maka router backup akan berjalan dengan otomatis menggantikan router primary, sehingga tidak akan ada putus koneksi pada jaringan[8]. Pada penerapanya digunakan sebuah metode failover dengan menggunakan protokol yang terdapat pada mikrotik router yaitu virtual router redundancy protocol (VRRP), virtual router redundancy protocol (VRRP) merupakan sebuah protokol yang digunakan untuk tujuan redudancy antar router yang menjalankan VRRP dengan menggunakan ID router virtual dengan menerapkan prioritas antar router[9]. Mikrotik router merupakan salah satu perangkat yang bisa digunakan sebagai gateway atau sebagai penghubung antar jaringan[10], selain sebagi gateway yang handal juga terdapat beberapa fitur yang sangat diperlukan dalam penggelolaan jaringan seperti firewall, DNS Server DHCP Server, bandwidth manajemen dan masih banyak fitur yang lainya[11].

$V R R P$ menggunkan failover dinamis untuk memastikan ketersediaan router yang aktif dengan menggunakan alamat $I P$ route default Virtual Router atau disebut $V R$, pada reudancy ini menyediakan cadangan alamat ip gateway 
sehingga jika router master $V R$ tidak tersedia lalu lintas jaringan akan dialihkan ke router backup secara otomatis tanpa ada pengaturan manual dari administrator jaringan[12].

Penelitian ini menggunakan beberapa referensi yang berkaitan dengan objek penelitian diantaranya yaitu, dengan penerapan protokol VRRP permasalahan pada router dapat teratasi, jika terjadi permasalahan pada router, downtime pada jaringan dapat dihindari[13]. Virtual router redudancy protocol (VRRP) pada jaringan berbasis Ipv6, perpindahan koneksi dari router utama ke router backup dapat dilakukan dengan baik sesuai dengan standar ITU-T[14].

Penerapan VRRP yang digunakan diantara dua router, memungkinkan router cadangan untuk mengganti router utama dengan segera tanpa menunggu waktu yang ditentukan, dengan biaya yang dikeluarkan cukup efektif untuk penerapkan metode ini[15].

Tujuan pada penelitian ini adalah untuk membuat sebuah sistem failover pada perangkat gateway yaitu router, jika terjadi permasalahan pada router maka akan ada router yang akan langsung mengantikan router tersebut, dengan penerapan ini diharapkan jika terjadi permasalahan pada perangkat router maka tidak akan menggangu penggunaan jaringan yang ada.

\section{METOdE PENELITIAN}

Pada penelitian ini digunakan beberapa tahap diantaranya yaitu studi literatur pada tahap ini dilakukan pengumpulan sumber literatur yang berkaitan dengan $V R R P$ dengan cara mempelajari teori dasar yang bersumber dari jurnal-jurnal atau buku yang berkaitan dengan penelitian. Sedangkan metode yang digunakan adalah metode pengembangan sistem, yang terdiri dari analisa kebutuhan sistem, desain, implementasi, dan pengujian. Pada tahap pertama yang dilakukan adalah melakukan analisa kebutuhan sistem dengan cara mengumpulkan kebutuhan-kebutuhan yang diperlukan untuk menerapkan failover pada router menggunakan protokol $V R R P$, sepesifikasi kebutuhan meliputi sepesifikasi perangkat keras dan perangkat lunak, pada perangkat keras seperti penentuan spesifikasi router yang akan digunakan, router yang digunakan yaitu routerboard mikrotik dengan tipe RB 1100Ahx2 dengan RouterOs versi 6 sebanyak dua buah, selanjutnya penentuan virtual router id, penentuan alamat ip interface vrrp, penentuan nilai priority antara kedua router, dan penentuan alamat ip untuk jaringan, sedangkan perangkat lunak yang dibutuhkan yaitu berupa aplikasi winbox yang digunakan untuk konfigurasi pada router dan aplikasi command prompt yang digunakan untuk pengujian koneksi.

Pada tahap kedua dilakukan desain jaringan dengan menentukan bentuk topologi jaringan yang akan digunakan dengan menyesuaikan kebutuhan yang akan diterapkan pada penelitian ini, pada tahap ini juga ditentukan router mana yang akan di jadikan sebagai router primary dan router backup. Tahapan ketiga melakukan implementasi berdasarkan desain yang sudah dibuat dengan cara melakukan konfigurasi pada kedua router yang telah di tentukan, dengan konfigurasi router pertama sebagai primary dan router kedua sebagai backup, pada konfigurasi router akan ditentukan priority dimana router dengan priority nilai lebih tinggi akan dijadikan sebagai router primary dan router dengan priority nilai lebih rendah akan dijadikan sebagai router backup.

Pada tahap keempat yaitu dilakukan pengujian terhadap konfigurasi yang sudah diterapkan pada sistem jaringan yang sedang berjalan, pengujian dilakukan dengan menggunakan aplikasi command prompt yang terdapat pada komputer client, pengujian dilakukan dengan cara mengirimkan paket ICMP ke router dengan cara melakukan tes koneksi ke router, selama pengujian salah satu router diputuskan dari koneksi ke switch, hal ini untuk membuktikan apakah konfigurasi VRRP sudah berjalan sesuai dengan perancangan yang diinginkan atau belum.

\section{HASIL DAN PEMBAHASAN}

Pada penelitian ini dilakukan mulai dari perancangan sistem jaringan sampai dengan pengujian jaringan pada penerapan failover gateway menggunakan protokol virtual router redundancy protocol (VRRP) pada mikrotik router, akan dijabarkan dalam beberapa bagian mulai dari analisa kebutuhan sistem, desain, implementasi sampai dengan pengujian.

\section{A. Analisa Kebutuhan Sistem}

Pada tahap analisa kebutuhan sistem ini dikumpulkan kebutuhan kebutuhan yang akan digunakan dalam penerapan sistem failover pada router menggunakan protokol VRRP diantaranya yaitu, dua buah routerboard mikrotik dengan tipe RB1100AHx2 dengan RouterOs versi 6.43.4, untuk pengalamatan perangkat router dan client digunakan alamat ip address 192.168.1.0/24, dan untuk alamat ip virtual pada interface VRRP yaitu 192.168.1.254/32 di konfigurasi pada kedua router yang akan digunakan sebagai gateway jaringan lokal, sedangkan untuk komunikasi antar router akan menggunakan sebuah virtual router ID dengan angka 45 pada masing-masing router, untuk menentukan router primary dan router backup yaitu dengan menambahkan priority pada masing-masing interface VRRP dengan ketentuan, pada router primary diberikan priority 254 , sedangkan pada router backup diberikan priority 100. Selain kebutuhan konfigurasi pada router dibutuhkan juga aplikasi pendukung untuk menerapkan sistem ini diantaranya aplikasi winbox versi 3.18 yang digunakan untuk konfigurasi router mikrotik, dan aplikasi command prompt pada microsoft windows yang digunakan untuk uji koneksi failover pada router.

\section{B. Desain}

Pada tahap desain dibuat rancangan topologi yang akan diterapkan pada perancangan ini, topologi yang digunakan yaitu menggunakan topologi star, pada topologi juga di lakukan pembagian alamt ip address untuk kedua router dan ip address untuk client (Gambar 1). Pada tahap ini juga di lakukan rancangan konfigurasi apa saja yang akan di lakukan pada router mulai dari penentuan alamat interface $V R R P$, virtual router $I D$, sampai dengan penetuan nilai priority pada masing-masing router. Selain konfigurasi VRRP, semua router juga di konfigurasi sebagai gateway dan dns server. 
Desain dari penerapan failover pada router menggunakan protokol VRRP (gambar 2), penentuan router primary akan dilakukan dengan melakukan pengecekan init state dimana jika nilai priority pada $V R R P$ adalah 254 maka ip akan mengirim paket advertisment dan broadcast permintaan ARP dan koneksi akan dialirkan pada master state atau router primary akan aktif dan sebaliknya jika berada pada status backup state jika ip pada jaringan mengirimkan paket advertisment dan broadcast permintaan ARP, maka backup state tidak akan menjawab permintaan $A R P$, jika router primary tidak aktif maka nilai priority 100 pada router backup yang akan dijadikan sebagai master state.

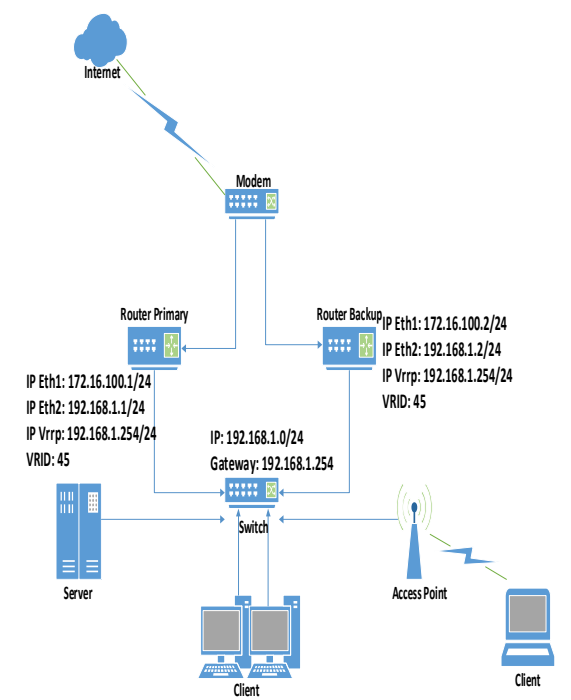

Gambar. 1 Topologi Jaringan Failover Menggunakan Protokol VRRP

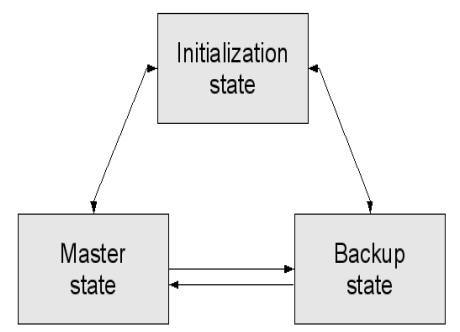

Gambar 2. VRRP State Transition Flow

\section{Implementasi}

Pada tahap implementasi akan dilakukan tahap konfigurasi pada router primary dan router backup, konfigurasi yang dilakukan pada router antara lain, seting Ip address, konfigurasi gateway, dns server, dan konfigurasi vrrp (Gambar 3), semua konfigurasi diterapkan pada kedua router yang ada.

1) 1). Konfigurasi Pada Router Primary: Pada router primary akan dikonfigurasi sebagai router gateway, dns server, dan konfigurasi pada interface VRRP, untuk penggunaan pengalamatan ip address pada router primary yaitu untuk interface ether1 dengan ip address 172.16.100.1/24, interface ether2 dengan ip address 192.168.1.1/24, dan untuk ip address interface vrrp adalah 192.168.1.254/32, dengan virtual router ID 45 dan priority dengan nilai 254, setelah konfigurasi VRRP pada router maka pada interface VRRP router primary statusnya yaitu RM atau running master.

Konfigurasi identity router dan interface:

/system identity

set name $=$ MT-Primary

/interface ethernet set [ find default-name=ether1] name=ether1@Internet speed=1Gbps

set [ find default-name=ether2 ] name=ether2@Lan speed $=1 \mathrm{Gbps}$

Konfigurasi ip address:

/ip address

add address=172.16.100.1/24 interface=ether1@Internet network $=172.16 .100 .0$

add address=192.168.1.1/24 interface=ether2@Lan network $=192.168 .1 .0$

add address $=192.168 .1 .254 / 32 \quad$ interface $=$ vrrp

network $=192.168 .1 .0$

Konfigurasi gateway:

/ip route

add check-gateway $=$ ping distance $=1$ gateway $=172.16 .100 .254$

/ip firewall nat

add action=masquerade chain=srcnat out-

interface=ether1@Internet

Konfigurasi dns server:

/ip dns

set servers $=172.16 .100 .254,8.8 .8 .8$

Konfigurasi vrrp:

/interface vrrp

add interface=ether2@Lan name=vrrp priority=254 vrid=45

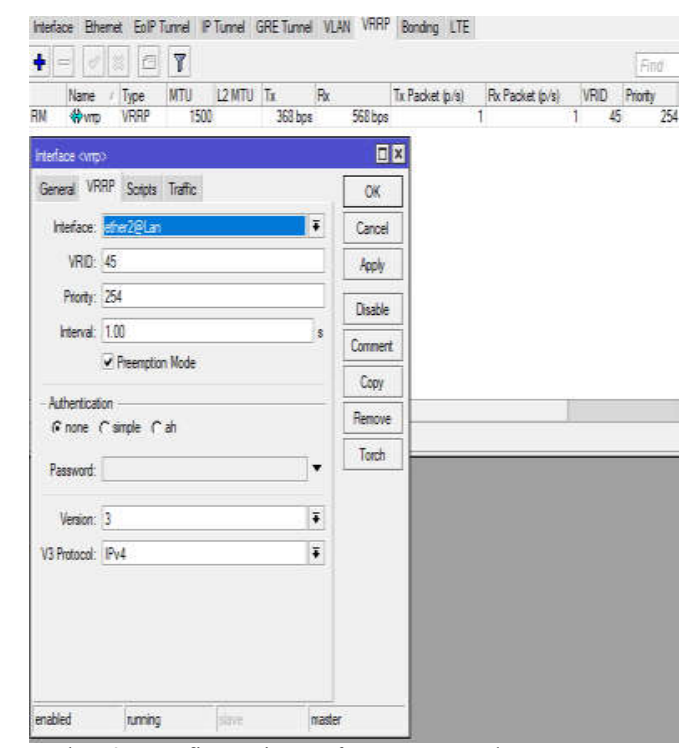

Gambar 3. Konfigurasi Interface VRRP Pada Router Primary

2). Konfigurasi Pada Router backup: Pada router backup akan dikonfigurasi sebagai router gateway, dns server, dan konfigurasi pada interface VRRP, untuk penggunaan pengalamatan ip address pada router backup yaitu untuk 
interface etherl dengan ip address 172.16.100.2/24, interface ether2 dengan ip address 192.168.1.2/24, dan untuk ip address interface vrrp adalah 192.168.1.254/32, dengan virtual router ID 45 dan priority dengan nilai 100, setelah konfigurasi pada interface VRRP maka pada interface VRRP router backup setatusnya akan B atau Backup.

Konfigurasi identity router dan interface:

/system identity

set name=MT-Backup

/interface ethernet

set [ find default-name=ether1 ] name=ether1@Internet speed $=1 \mathrm{Gbps}$

set [ find default-name=ether2 ] name=ether2@Lan speed $=1 \mathrm{Gbp}$

Konfigurasi ip address:

/ip address

add address=172.16.100.2/24 interface=ether1@Internet network $=172.16 .100 .0$

add address=192.168.1.2/24 interface=ether2@Lan network $=192.168 .1 .0$

add address $=192.168 .1 .254 / 32 \quad$ interface $=$ vrrp

network=192.168.1.

Konfigurasi gateway:

ip route

add check-gateway= $=$ ping distance $=1$ gateway $=172.16 .100 .254$

/ip firewall nat

add action=masquerade chain=srcnat out-

interface=ether1@Internet

Konfigurasi dns server:

/ip dns

set servers $=172.16 .100 .254,8.8 .8 .8$

Konfigurasi vrrp:

/interface vrrp

add interface $=$ ether $2 @$ Lan name=vrrp priority $=100$ vrid $=45$

\section{Pengujian}

Pada pengujian akan dilakukan dengan menggunakan aplikasi command prompt yang terinstal pada client microsoft windows, pengujian akan dilakukan dengan beberapa tahap yang pertama yaitu pengujian pada saat router primary yang dijadikan sebagai default gateway, dan router backup dalam kondisi standby, tahap yang kedua pengujian pada saat router primary down dan router backup yang akan di jadikan sebagai default gateway.

1). Pengujian Pada Router Primary: Pada pengujian tahap pertama dilkukan dengan kondisi semua router baik router primary maupun router backup dalam kondisi standby, dan tidak ada ganguan pada kedua router (gambar 5), pengujian akan dilakukan dengan cara melakukan test koneksi ke jaringan internet pada komputer client dengan menggunkan aplikasi command prompt dengan melakukan tracerout ke domain web tertentu untuk mengetahui gateway dari router mana yang akan digunakan untuk akses ke internet.
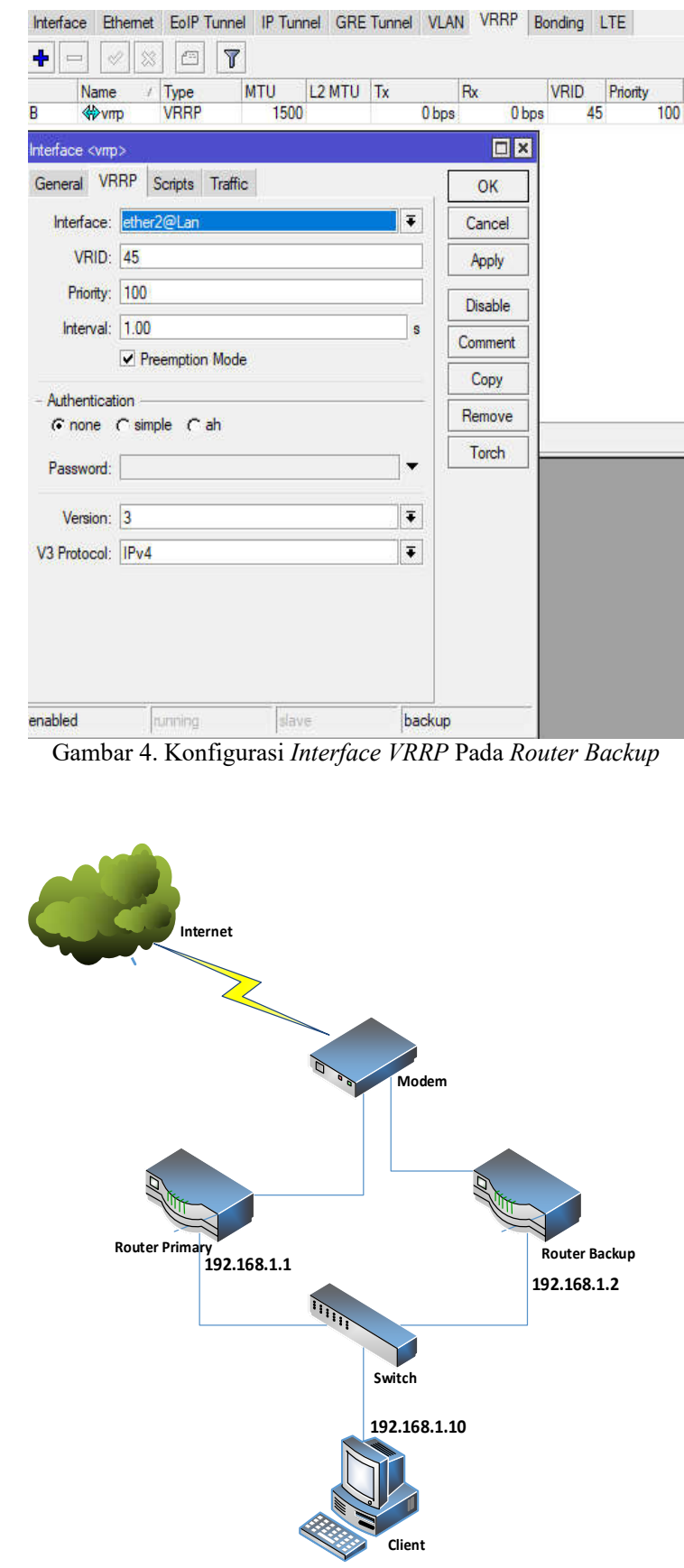

Gambar 5. Topologi Kedua Router Up

Dari hasil pengujian pertama (gambar 6) didapatkan bahwa ketika ada client meminta koneksi ke internet, maka akan langsung di arahkan pada alamat ip address 192.168.1.1, yaitu alamat ip dari router primary, walaupun kondisi router backup dalam keadaan aktif, hal ini dikarenakan ada perbedaan pada konfigurasi nilai priority pada interface VRRP dimana nilai priority router primary lebih besar dibandingkan nilai priority router backup, sehingga router primary akan dijadikan sebagai default gateway. 


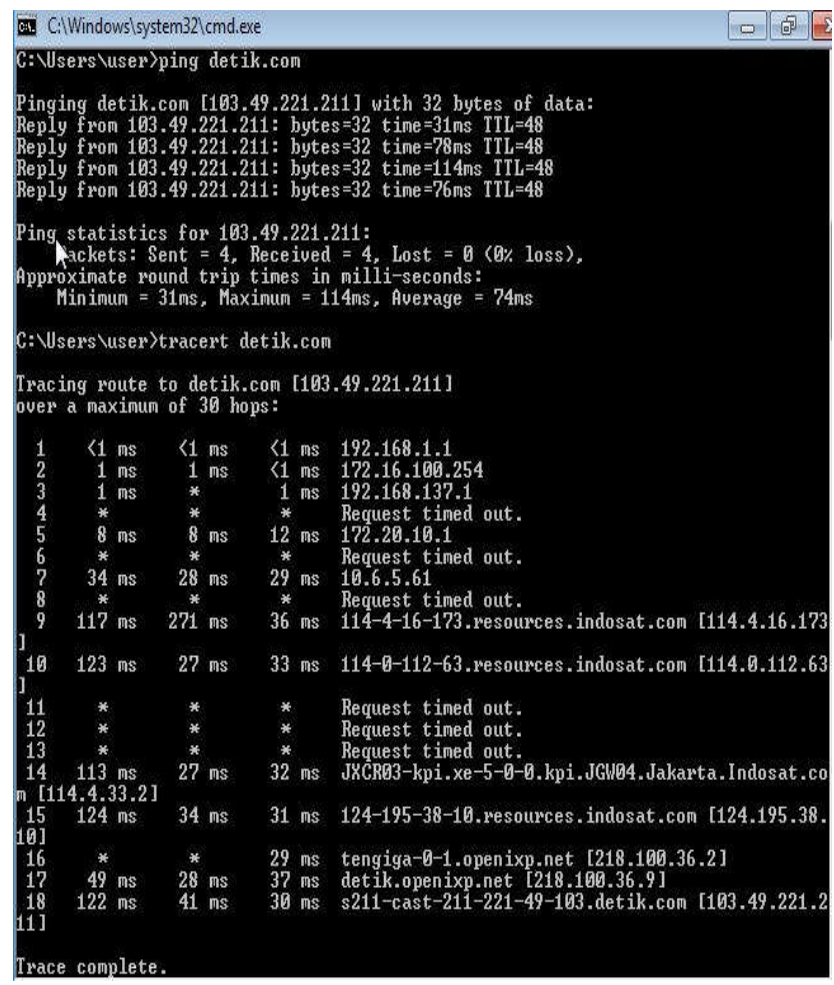

Gambar 6. Hasil Tracerout Kedua Router UP

TABEL I

HASIL PENGUJIAN ROUTER PRIMARY

\begin{tabular}{|c|c|c|c|}
\hline Router & Status & Priority & Gateway \\
\hline Router Primary & $U P$ & 254 & Aktif \\
\hline Router Backup & $U P$ & 100 & Non Aktif \\
\hline
\end{tabular}

2). Pengujian Pada Router Backup: Pada pengujian tahap kedua akan dilakukan pemutusan koneksi dari switch ke router primary, sedangkan router backup dalam keadaan standby (gambar 7), untuk pengujian hasil test koneksi juga sama dengan pengegujian pada tahap pertama yatu dengan cara menggunkan aplikasi command prompt pada komputer client dengan melakukan tracerout ke domain web tertentu untuk mengetahui gateway dari router mana yang akan digunakan untuk akses internet, selain tracerout, juga akan dilakukan pengetesan koneksi dengan printah ping.

Hasil dari pengujian kedua (Gambar 8), pada saat client sedang terkoneksi ke internet dan tiba-tiba router primary mengalami permasalahan atau down maka koneksi akan langsung dialihkan ke router backup secara otomatis, dapat di lihat pada percobaan kedua saat client melakukan tracerout ke detik.com dari command prompt koneksi langsung diarahkan ke router backup dengan default gateway 192.168.1.2, hal ini disebabkan interface VRRP pada router backup, saat router primary mengalami masalah atau down maka status interface VRRP pada router backup yang sebelumnya $B$ atau backup akan berubah menjadi $R M$ atau running master, status $R M$ pada interface VRRP router backup akan bertahan selama router primary tidak bisa di akses atau down, saat router primary sudah up kembali maka status pada interface VRRP router backup akan kembali menjadi $B$ kembali (gambar 9).

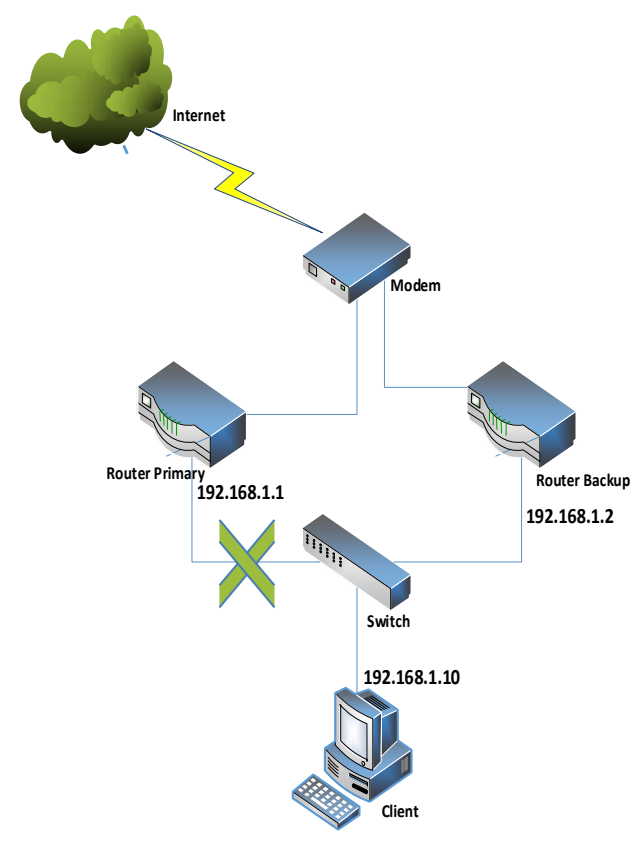

Gambar 7. Topologi Salah Satu Router Down

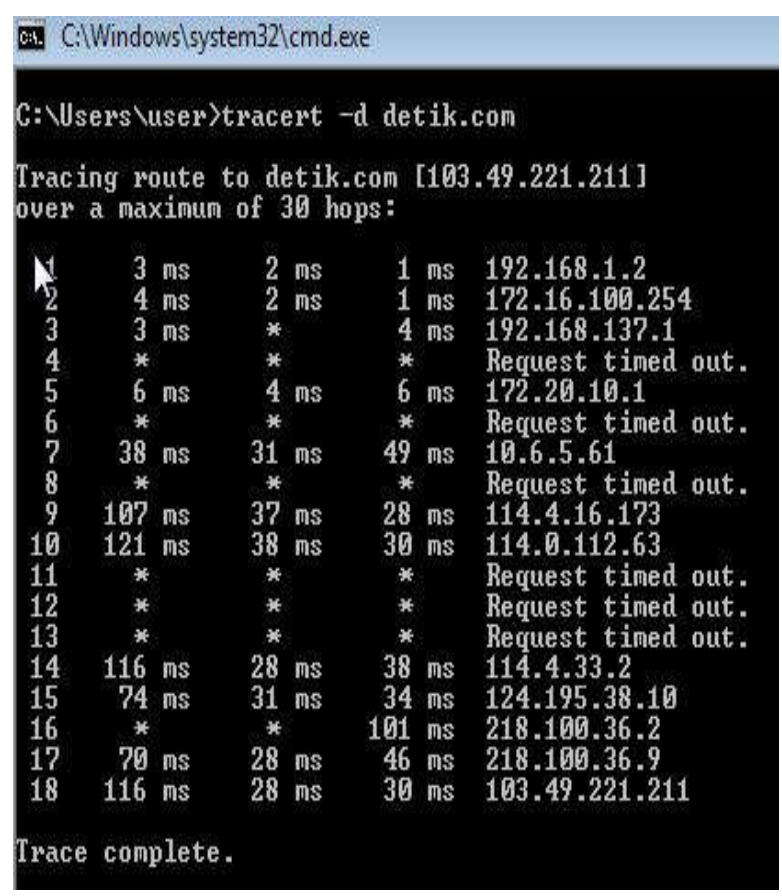

Gambar 8. Hasil Tracerout Router Primary Down

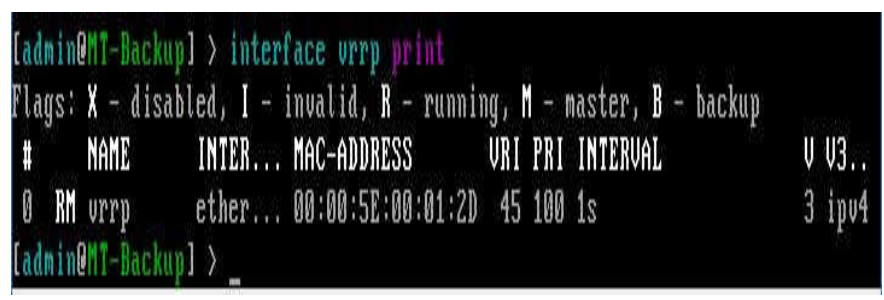

Gambar 9. Status Router Backup 
Jika di lakukan pengetesan menggunakan printah ping pada aplikasi command prompt pada saat router primary mengalami masalah atau down maka akan terjadi request time out sebanyak satu kali atau sekitar 1 detik (gambar 10), hal ini menunjukan karena adanya perpindahan koneksi dari ip gateway 192.168.1.1 router primary ke ip gateway 192.168.1.2 router backup.

\section{C: Windowslsystem32land.exe}

\section{C:VUsers \user >ping 8.8.8.8-t}

Pinging 8.8 .8 .8 with 32 bytes of data:

Reply from $8.8 .8 .8:$ bytes $=32$ time $=129 \mathrm{~ms}$ TTL $=117$

Reply from 8.8.8.8: bytes $=32$ time $=57 \mathrm{~ms}$ TTL $=117$

Reply from 18.8 .8 : bytes $=32$ time $=107 m s$ TTL $=117$

Reply from $6: 8.8 .8$ : bytes $=32$ time $=141 \mathrm{~ms}$ TTL $=117$

Reply from 8.8 .8 .8 : bytes $=32$ time $=125 \mathrm{~ms}$ TTL $=117$

Reply from 8.8.8.8: bytes $=32$ time $=44 \mathrm{~ms}$ TTL $=117$

Reply from 8.8 .8 .8 : bytes $=32$ time $=133 \mathrm{~ms}$ TTL $=117$

Reply from 8.8.8.8: bytes $=32$ time $=131 \mathrm{~ms}$ TTL $=117$

Request timed out.

Reply from 8.8 .8 .8 : bytes $=32$ time $=123 \mathrm{~ms}$ TTL $=117$

Reply from 8.8.8.8: bytes $=32$ time $=130 \mathrm{~ms}$ TTL $=11$ ?

Reply from 8.8.8.8: bytes $=32$ time $=130 \mathrm{~ms}$ TTL $=117$

Reply from 8.8.8.8: bytes $=32$ time $=128 \mathrm{~ms}$ TTL $=117$

Reply from 8.8.8.8: bytes $=32$ time $=128 \mathrm{~ms}$ TTL $=117$

Reply from 8.8.8.8: bytes $=32$ time $=125 \mathrm{~ms}$ TTL $=117$

Reply from 8.8 .8 .8 : bytes $=32$ time $=88 \mathrm{~ms}$ TTL $=117$

Reply from $8.8 .8 .8:$ bytes $=32$ time $=127 \mathrm{~ms}$ TTL $=117$

Ping statistics for 8.8 .8 .8 :

Packets: Sent $=17$, Received $=16$, Lost $=1(5 \%$ loss $)$,

Approximate round trip times in milli-seconds:

Minimum $=44 \mathrm{~ms}$, Maximum $=141 \mathrm{~ms}$, Average $=115 \mathrm{~ms}$

Gambar 10. Hasil Ping Saat Router Primary Down

TABEL II

HASIL PENGUJIAN ROUTER BACKUP

\begin{tabular}{|c|c|c|c|}
\hline Router & Status & Priority & Gateway \\
\hline Router Primary & Down & 254 & Non Aktif \\
\hline Router Backup & UP & 100 & Aktif \\
\hline
\end{tabular}

\section{KESIMPULAN}

Dari penelitian yang sudah dilakukan dengan penerapan failover gateway menggunakan protokol virtual router redundancy protocol (VRRP) pada mikrotik router, penggunaan jaringan akan lebih maksimal dan penggunaan jaringan tidak akan terpengaruh jika ada salah satu router yang bermasalah, jaringan akan tetap terkoneksi selama router primary bermasalah, hali ini akan mempermudah dalam perbaikan router primary dikarenakan koneksi jaringan client akan otomatis diarahkan ke router backup, penerapan sistem ini cocok untuk jaringan yang pemakaian trafiknya sangat tinggi sehingga tidak akan menggagu koneksi jaringan jika terjadi permasalahan pada router. Walupun penerapan sistem failover menggunakan $V R R P$ sudah cukup bagus akan lebih sempurna lagi jika digabungkan dengan sistem monitoring jaringan yang dihubungkan dengan perangkat smartphone baik dengan aplikasi email ataupun aplikasi masagge, sehingga jika terjadi permasalahan pada perangkat router akan lebih cepat terdeteksi.

\section{UCAPAN TERIMA KASIH / ACKNOWLEDGMENT}

Pada kesempatan ini penulis mengucapkan banyak trimakasih pada staff IT STMIK Nusamandiri yang telah banyak membantu dalam menyediakan peralatan jaringan yang digunakan sebagai bahan penelitian, sehingga penelitian ini dapat selesai dengan hasil maksimal.

\section{REFERENSI}

[1] W. H. Pamungkas and E. Prayitno, "PERANCANGAN JARINGAN REDUNDANCY LINK MENGGUNAKAN KONSEP HSRP DAN ETHERCHANNEL," vol. 2, no. 1, pp. 75-82, 2018.

[2] N. A. Rakhmawati, F. Samopa, and R. M. Ijtihadie, "Perangkat Lunak Semi Hot Standby Router Protocol Pada Pc Router Berbasis Linux," JUTI J. Ilm. Teknol. Inf., vol. 4, no. 1, p. 24, 2005.

[3] H. L. Sari, A. Sudarsono, and B. H. Haryadi, "PENGEMBANGAN JARINGAN LOCAL AREA NETWORK MENGGUNAKAN SISTEM OPERASI LINUX REDHAT 9," J. Media Infotama, vol. 9, no. 1, 2013.

[4] D. Kurniawan, W. Wardhana, and N. A. Ito, "Penggabungan Dua ISP Guna Menstabilkan Koneksi Internet Dengan Metode Failover," J. Komputansi, vol. 4, no. 2, pp. 1-11, 2016.

N. D. Anwar, L. V. Yovita, and R. Mayasari, "IMPLEMENTASI DAN ANALISA PERFORMANSI REDUNDANCY PADA JARINGAN MULTICAST DENGAN METODE PROTOCOL INDEPENDENT MULTICAST," in $e$ Proceeding of Engineering, 2015, vol. 2, no. 3, pp. 7159-7166.

[6] E. K. Pratama, F. N. Hasan, and K. M. Asteroid, "PEMANFAATAN REDUDANCY ROUTER DENGAN FITUR VRRP MIKROTIK PADA JARINGAN THIN CLIENTNo Title," J. AKRAB JUARA, vol. 3, no. 2, pp. 21-29, 2018.

[7] R. Munadi, R. M, and K. Nugroho, "ANALISIS MEKANISME REDUNDANCY GATEWAY DENGAN MENGGUNAKAN PROTOKOL HSRP DAN VRRP," in Digital Information \& System Conference 2012, 2012, pp. 93-98.

[8] A. I. Harsapranata, "Implementasi Failover Menggunakan Jaringan Vpn Dan Metronet Pada," Implementasi Fail. Menggunakan Jar. Vpn Dan Metronet Pada Astrindo Indones., vol. 8, no. 2, pp. 66-77, 2015.

[9] W. Mikrotik, "VRRP," 2018. [Online]. Available: https:/wiki.mikrotik.com/wiki/Manual:Interface/VRR P. [Accessed: 30-Oct-2018]. 
[10] R. Pambudi and M. A. Muslim, "Implementasi Policy Base Routing dan Failover Menggunakan Router Mikrotik untuk Membagi Jalur Akses Internet di FMIPA Unnes," J. Teknol. dan Sist. Komput., vol. 5, no. April, pp. 57-61, 2017.

[11] F. J. Bhayangkara and I. Riadi, "IMPLEMENTASI PROXY SERVER DAN LOAD BALANCING MENGGUNAKAN METODE PER CONNECTION CLASSIFIER ( PCC ) BERBASIS MIKROTIK ( Studi kasus : Shmily . net )," J. Sarj. Tek. Inform., vol. 2, no. 2, pp. 1206-1217, 2014.

[12] P. Rajamohan, "An Overview of Virtual Router Redundancy Protocol Techniques and Implementation for Enterprise Networks," vol. 1, no. 9, pp. 554-562, 2014.

[13] M. Y. Choirullah, M. Anif, and A. Rochadi, "Analisis Kualitas Layanan Virtual Router Redundancy Protocol Menggunakan Mikrotik pada Jaringan VLAN," Jnteti, vol. 5, no. 4, pp. 278-285, 2016.

[14] A. Iriansyah and D. W. Chandra, "Penerapan Virtual Router Redundancy Protocol Pada Mikrotik Berbasis IPv6 Untuk Meningkatkan Performansi Quality Of Service," no. 672010046, 2017.

[15] H. Matsuda, "L2 Switch Feature for Virtual Router Redundancy Protocol Fast Convergence," vol. 55, no. 11, pp. 2-4, 2012. 